\title{
CAMBIAL ACTIVITY AND DEVELOPMENT OF XYLEM IN TAMARINDUS INDICA L. GROWING IN DIFFERENT FORESTS OF GUJARAT STATE
}

\author{
K. S. RAJPUT and K. S. RAO \\ Dept Biosciences, Sardar Patel University, Vallabh Vidyanagar-388 120, India; \\ E-mail:kayesrao@yahoo.com
}

(Received 5 December, 2000)

\begin{abstract}
Seasonal behaviour of vascular cambium and development of xylem were investigated in Tamarindus indica L. growing in moist deciduous (MDF), dry deciduous (DDF) and scrubland (SF) forests of Gujarat state. The cambium was storied when dormant and gradually the storied arrangement was lost with the initiation of cambial activity and became non-storied when the activity reached peak. Development of xylem continued for ten months in MDF, eight months in DDF and nine months in SF. Activity started in June and July in MDF and DDF, respectively, and maximal growth was seen only after the first shower of rains in July and October in MDF and August in DDF. Cambial cells ceased to divide in March and February in MDF and DDF, respectively. In SF, cambial cells began to divide in May and reached peak in September-October during the monsoon and the divisions ceased in January. Cambial cell division and differentiation of xylem were found suspended in April-May in MDF, March-June in DDF and February-April in SF. Cambial activity and xylem development are correlated with local climatic conditions and phenology of the trees.
\end{abstract}

Key words: cambium, phloem, xylem, Tamarindus indica

\section{INTRODUCTION}

Tamarindus indica L. are the moderate sized evergreen trees, grown for their edible fruits, which are rich source of vitamin $C$ and forms an important ingredient of curries in most parts of India. Bark is the source of tannin and wood is used for agricultural implements, tool handles, wheels, rice ponders, etc., and also employed for constructional purposes and has been recommended as substitute for Teak and Sal for beams, rafters and trusses (Anonymous 1986).

The most widely held concepts concerning climatic control of tree growth and cambial activity are based on observations on temperate trees where seasonal variations in temperature constitutes the principal climatic driving variable. In contrast, in tropical climate long and severe dry season, rainfall seasonality constitutes the primary climatic determinant of the 
phenology (Borchert 1999). Therefore cambium activity in tropical trees is relatively long where the radial growth continues either throughout the year (Fahn 1982, Dave and Rao 1982a, Ajmal and Iqbal 1987, Rajput 1997) or for the major part of the year (Dave and Rao 1982b, Iqbal and Ghouse 1985, Rajput and Rao 2000). However, similar species growing under different local climatic conditions show significant variation in periodicity of cambium and in the production of xylem and phloem (Rajput 1997, Rajput and Rao 2000, Rao and Rajput 1999). In this connection trees of Tamarindus indica growing in moist deciduous, dry deciduous and scrubland forests are selected in the present investigation to understand the response of vascular cambium and xylem production under different climatic regions.

\section{MATERIALS AND METHODS}

Samples of cambial tissues together with inner bark and outer sapwood were collected from the main trunk at breast height of 15-20 years old trees of Tamarindus indica having similar trunk diameter. These trees were naturally growing in moist deciduous forest (MDF) at Waghai in Dangs, dry deciduous forest (DDF) at Pavagadh, and scrubland forest at Bhuj and Nakhatrana in Kutch. Periodic collections were made at monthly intervals from January to December 1994. Two trees were sampled each time to obtain four blocks and no tree being sampled more than once. The blocks measuring about $60 \mathrm{~mm} \times 20 \mathrm{~mm}$ were excised with the help of hammer, chisel and grafting knife and fixed immediately in FAA (Berlyn and Miksche 1976). Suitably trimmed small pieces of these blocks were sectioned in transverse, radial and tangential longitudinal planes at 15 to 20 $\mu \mathrm{m}$ thick on a sliding microtome. After staining with tannic acid-ferric chloride-lacmoid combination (Cheadle et al. 1953), sections were mounted in DPX after passing through ethanol-xylene series.

The term's cambial zone and cambium are used to include the entire population of ray and fusiform cambial cells between the xylem and phloem. Cambial activity was determined by counting the number of undifferentiated layers of cambium lying between xylem and phloem in transverse sections. One hundred measurements of cambial layers at random were selected to obtain the mean and standard deviation.

Seasonal phenological changes of the trees were recorded at the time of each sample collection. Data on air temperature and rainfall were obtained from the Indian Meteorological Department, Ahmedabad. 


\section{RESULTS}

\section{Structure of cambium}

The cambium was storied during dormant period (Fig. 1A) and gradually the storied arrangement was lost with the initiation of cambial activity and became non-storied when the activity reaches its maxima (Fig. 1B). The axially elongated fusiform cambial cells were relatively short measuring about 334-388 $\mu \mathrm{m}$ in MDF, 306-381 $\mu \mathrm{m}$ in DDF and 299-369 $\mu \mathrm{m}$ in SF. Cambial rays were homocellular and mostly uni-biseriate but triseriate rays were also observed occasionally. Cambial ray height differed from 186-259 $\mu \mathrm{m}$ in MDF, 177-234 $\mu \mathrm{m}$ in DDF and 180-275 $\mu \mathrm{m}$ in SF. The radial walls of fusiform cambial cells were relatively thick (Fig. 1C) with conspicuous beaded nature during the dormant condition. The walls were thin and relatively less beaded when the cambium was active. Ray cambial cells appeared polygonal and compactly arranged during active condition, while they were oval to oblong with conspicuous intercellular spaces when dormant.

\section{Cambial activity}

Prior to the initiation of activity cambial cell underwent swelling followed by periclinal divisions in June in moist deciduous forest (MDF) (Fig. $1 \mathrm{D}, \mathrm{E})$. Activity reached peak twice in July and October with 12-18 number of cambial cells in each radial file (Fig. 1F). Then activity declined in the succeeding months and ceased in March (Fig. 2A). Compared to MDF, radial growth in the trees growing in dry deciduous forest (DDF) delayed by one month and ceased earlier. In DDF, activity started in July and ceased in February after reaching peak in August (Fig. 2B). Inception of cambial activity in scrubland forest (SF), was noticed earlier than both the forests, i.e. in May (Fig. 2E) and reached peak in September-October with 8-14 cells in each radial file. Activity was declined gradually and ceased in January (Fig. 2F). Cambial zone remained narrow with 4-6 cells in April-May, March-June and February-April in MDF, DDF and SF, respectively (Fig. 1C, 2B,D). 


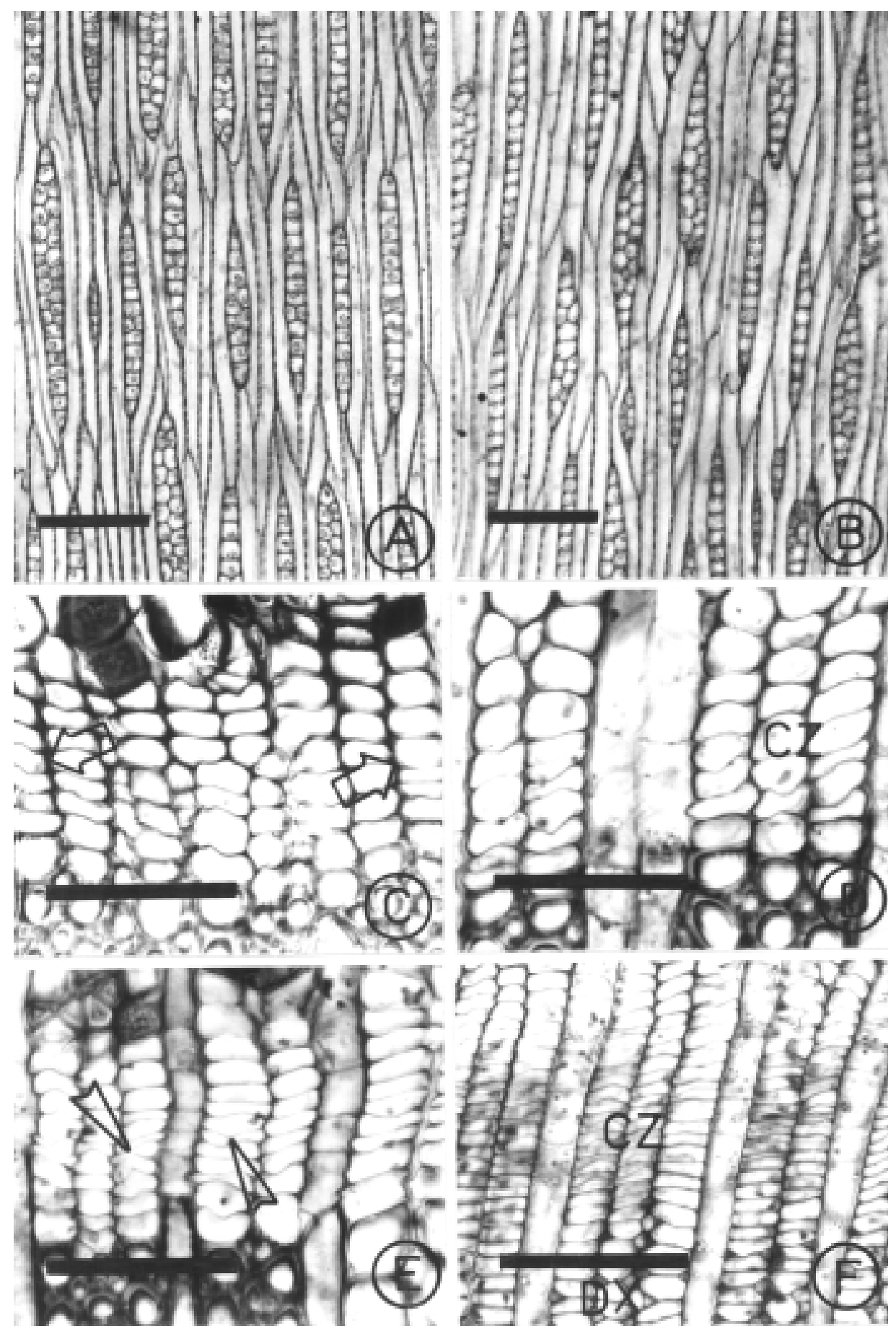


Phenology of the trees

Being an evergreen tree Tamarindus does not shed all the leaves at a time. In all the three forests yellowing of mature leaves and defoliation started in March followed by development of floral buds and new leaves in April-May. The entire crown of old leaves was replaced by new crop of leaves in June. Fruit setting and maturation of fruits was seen in July-August and October-November, respectively.

\section{Climatic factors}

The state of Gujarat is famous for its varying climatic conditions ranging from moist deciduous (southern part) to pure desert conditions (Kutch). As the tropic of cancer passes through the northern border of the state, winters are severe and summers are oppressively hot with wide range of diurnal temperature. The hottest months of the year are April-May throughout the state. The maximum temperature varies in different parts of the state being lowest in southern part $\left(37^{\circ} \mathrm{C}\right)$ than the central and northern parts $\left(40.5^{\circ} \mathrm{C}\right)$. State experiences winter from November to February with December-January being the coldest months (Fig. 3B). The monsoon months are June to September with maximum rains in July closely followed by August and few light showers some times in the first week of October. In general rainfall is more in southern part $(1252-3162 \mathrm{~mm})$ than other parts of the state and lowest in Kutch $(80-153 \mathrm{~mm})$. The dry weather continues from November to May (Fig. 3A).

\section{Development of vascular tissues}

Development of xylem and phloem elements began simultaneously with the initiation of cambial activity in all the three forests. In MDF, xylem production started with the initiation of cambial cell division and culmi-

Fig. 1. Tangential longitudinal (A, B) and transverse view (C-F) of cambium of Tamarindus indica. A: Cambial cells in February showing storied arrangement of fusiform cambial cells in DDF. B: Cambial cells in October showing nonstoried arrangement of fusiform cambial cells in MDF. C: Dormant cambium in April from MDF. Cambial zone is surrounded by mature xylem and phloem elements. Note the thick radial walls (arrows) of cambial cells. D: Swelling of cambial cells in June prior to the initiation of cambial cell division in MDF. E: Initiation of cambial cell division in June from MDF. The narrow cells in the middle of cambial zone show recently formed thin tangential walls (arrowheads). F: A cambial zone with differentiating xylem and phloem elements from MDF in July. CZ = Cambial zone, DX

$=$ Differentiating xylem. Scale bar $=150 \mu \mathrm{m}$ for Fig. 1A-B, and $75 \mu \mathrm{m}$ for Fig. 1C-F 

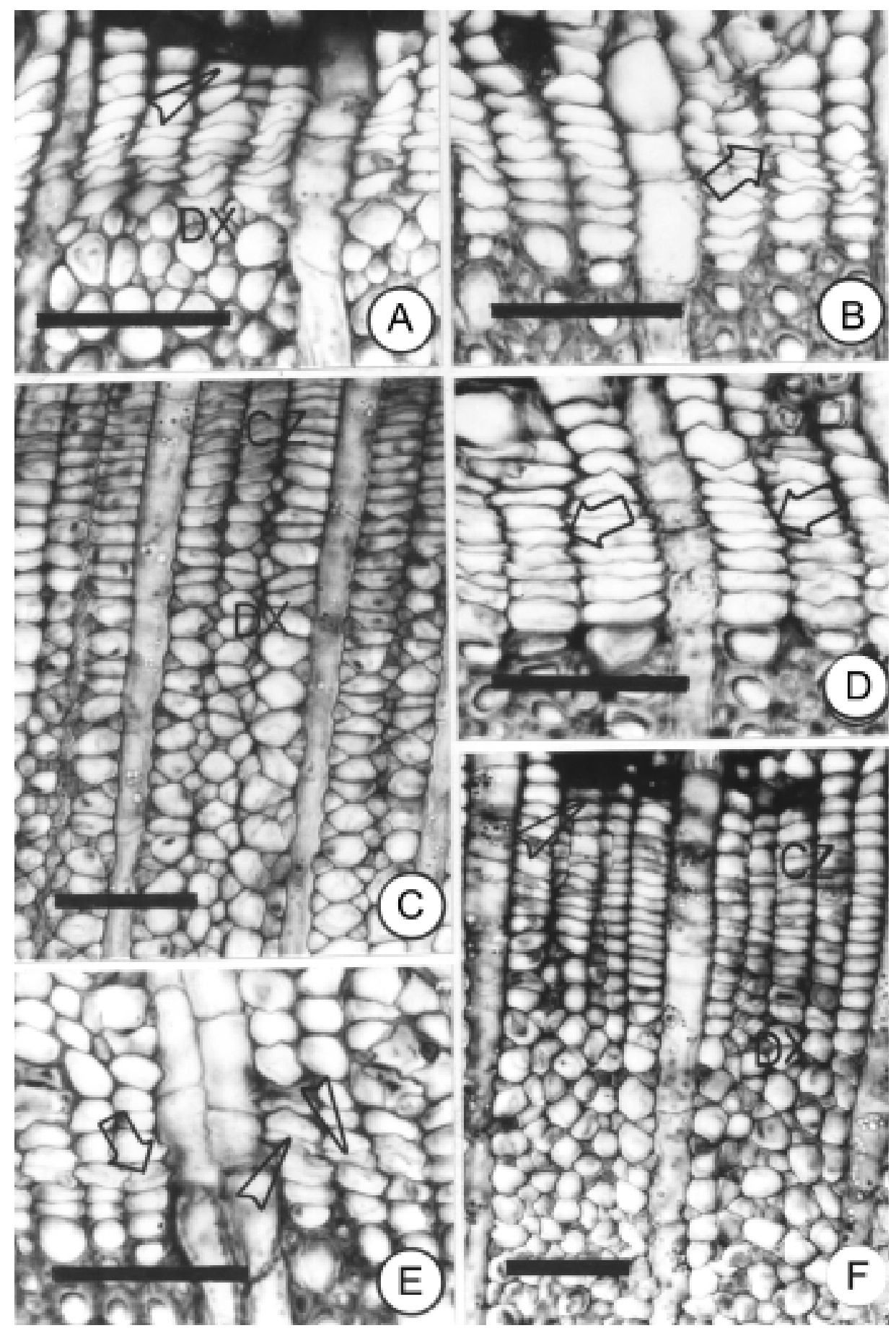
nated in July and October with 25-30 number of differentiating xylem and 3-5 phloem elements. Differentiation of xylem and phloem declined with the cessation of cambial activity. Although, the cambial cells ceased to divide in March the differentiation and maturation of xylem elements continued. In DDF, xylem development began in July and culminated in August-September with 20-28 differentiating xylem derivatives. However, compared to MDF, development of xylem was less in DDF. In SF, although the cambial activity and wood formation began in May, rapid differentiation of xylem and phloem elements started only after the first shower of rains in June. Xylem and phloem development culminated in September-October with 18-22 differentiating xylem and 3-5 phloem elements. Xylem and phloem development then declined in the following months and cambial zone was found surrounded by mature xylem and phloem elements in February.

\section{Xylem structure}

In all the three forests xylem was diffuse porous with indistinct growth rings. However, annual amount of xylem increment can be discerned by the tangential layer of initial parenchyma and crystaliferous fibres formed at the end of cambial activity. The axial parenchyma were vasicentric and aliform to confluent. Vessels were mostly solitary but radial multiples of 3-6 cells were also observed occasionally. The length and lumen diameter of the vessel elements varied from 193-259 $\mu \mathrm{m}$ and 130-190 $\mu \mathrm{m}$ respectively in all the three forests.

\section{DISCUSSION}

Occurrence of storied cambium is considered as an advance feature and reported in some tropical trees (Rao and Dave 1984, Rao et al. 1996,

Fig. 2. Transverse view of cambium with xylem and phloem of Tamarindus indica. A: Cessation of cambial cell divisions in March from MDF. Note the completion of phloem development while xylem elements are still undergoing maturation. B: Dormant cambium in May from DDF. Note the thick radial walls (arrow). C: Differentiating xylem elements in August during the grand period of cambial activity in DDF. D: Narrow cambial zone in February, surrounded by mature xylem and phloem elements in SF. E: Swelling of fusiform cambial cells (arrow) followed by periclinal divisions in May from SF. Note the recently formed thin tangential walls. F: Cessation of phloem development in January marked by occurrence of parenchyma with phenolic contents close to cambial zone in SF. Note that the development of xylem is continued. $\mathrm{CZ}=$ Cambial zone, $\mathrm{DX}=$ Differentiating xylem. Scale bar $=75 \mu \mathrm{m}$ 
Rajput and Rao 1996). Storied pattern of fusiform cambial cells has originated in number of phylads of dicotyledons independently, presence of storing does characterize certain groups of families commonly thought to be closely related (Carlquist 1988). Genera studied so far from Fabaceae possess storied cambium but most of the members of the Caesalpinaceae are having nonstoried cambium. The cambium of Tamarindus, growing in all the three forests, is storied during dormant condition and lost its storied arrangement with the initiation of cell divisions. The anticlinal divisions in the fusiform cambial cells are not perfectly longitudinal from one tip to the another resulting the unequal elongation of daughter cells that results the loss of storied arrangement in the cambium.
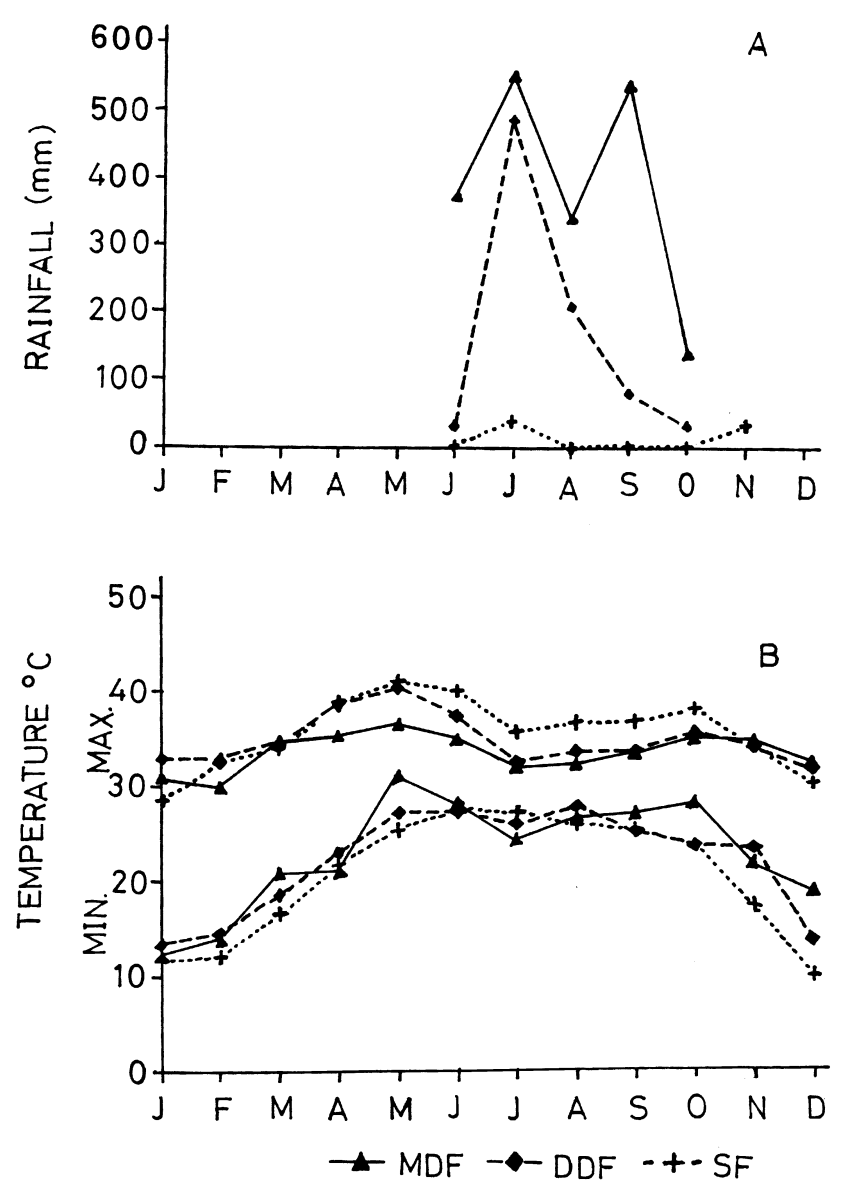

Fig. 3. Graphic representation of average rainfall (A) and temperature (B) in MDF, DDF and SF recorded at Indian Meteorological Centre, Ahmedabad in the year 1994 
The occurrence of intercellular spaces is not common in cambium, such spaces do exist among the ray cells of some species (Rajput and Rao 1998). In the present study intercellular spaces encountered during the drier part of the year and development of these spaces may be in response to water scarcity. Under high temperature, when water is limiting factor, daily water stress results in dehydration and loss of liquid water film from the rays. This results in the conversion of fully hydrated and turgid ray cells to cells almost spherical in shape, forming large intercellular spaces at their corners which help in free gas exchange (Rajput and Rao 1998).

In temperate climate each cycle of seasonal development of xylem and phloem starts with the bud break in spring and ends prior to the leaf shedding. Consecutive cycles are separated by rest period imposed by winter cold. Similarly in Mediterranean climate active growth occurs during mild and wet winter and spring followed by a period of dormancy during dry and warmer season (Liphschitz and Lev-Yadun 1986). However, in tropical conditions cambium remains active throughout (Dave and Rao 1982a, Fahn 1982, Rajput and Rao 2000) or for the major part of the year (Fahn and Sarnet 1963, Waisel and Fahn 1965, Dave and Rao 1982b, Rao and Rajput 1999). Tamarindus being an evergreen tree undergoes radial growth for the major part of the year in all the three forests.

Like other evergreen trees (Fahn et al. 1968, Dave and Rao 1982a, Paliwal and Paliwal 1990, Rajput and Rao 2000) the correlation between extension growth and radial growth is not clear in Tamarindus. Although sprouting of new leaves and development of flower buds starts in April-May cell division in cambial zone commences only in June and July in MDF and DDF, respectively. Whereas in SF, divisions in cambium are encountered in May. Similar observations are also made in Acacia nilotica growing in MDF and SF in which inception of cambial cell divisions vary, while cambium was found active throughout the year in DDF (Rajput and Rao 2000).

In Tamarindus growing in MDF and DDF, cambial activity starts only after the arrival of first shower of rains in June and peaks in August when the rains are heavy. In SF, cambial activity commences in May prior to the first shower of rains and maximal growth is seen in September-October at the end of monsoon. Compared to MDF and DDF annual precipitation is very less in SF and therefore, maximal radial growth at the end of monsoon may be associated with sufficient availability of ground water. Ground water availability plays an important role in controlling the activity of cambium. Water stress directly inhibits the cambial activity by reducing 
the turgor pressure of the cells and indirectly inhibits it by reducing the growth of the leaves and apical meristem thereby reducing the supply of hormones and assimilates required for the process (Little 1975). Among the various environmental factors, the effect of temperature is considered as a factor of primary importance for activating the cambium following its effect on bud opening and subsequent growth (Kramer and Kozlowski 1979). In all the three forests, development of floral buds and sprouting of new leaves began in April-May, when the temperature recorded is maximum for the year. However, in MDF and DDF, development of xylem commenced in June and July, respectively, while in SF, xylem production starts in May when the temperature is maximum. As recorded in Ficus rumphii (Ajmal and Iqbal 1987) cambial reactivation occurs four to six weeks after the emergence of new leaves in both MDF and DDF. This might be due to the fact that leaf emergence is accompanied by fruit set till June-July, and hence growth hormones produced by young leaves might be at first utilised in the reproductive phase of growth and be available to reactivate the cambium only afterwards. Similar observations are made in Prosopis spicigera (Iqbal and Ghouse 1985) and in Gmelina arborea (Dave and Rao 1982b). Trees of different species growing under similar climatic conditions may behave differently with regard to cambial activity and xylem and phloem differentiation (Ajmal and Iqbal 1987). Similarly it appears that same species growing under different climatic condition may behave differently with regard to cambial activity and mode of xylem and phloem differentiation. It seems true that cambial periodicity is controlled by complex of factors rather than single factor (Alvim 1964).

Acknowledgement - Authors are thankful to University Grants Commission, New Delhi for financial support.

\section{REFERENCES}

Ajmal, S. and Iqbal, M. (1987): Seasonal rhythm of structure and behaviour of vascular cambium in Ficus rumphii. - Ann. Bot. 60: 649-656.

Alvim, P. D. T. (1964): Tree growth and periodicity in tropical climate. - In: Zimmermann, M. H. (ed.): Formation of wood in forest trees. Acad. Press, New York, pp. 479-495.

Anonymous (1986): The useful plants of India. - Publication and Information Directorate, Council of Scientific and Industrial Research (CSIR), Hill side Road, New Delhi.

Berlyn, G. P. and Miksche, J. P. (1976): Botanical microtechnique and cytochemistry. - Iowa State Univ. Press, Ames, Iowa. 
Borchert, R. (1999): Climatic periodicity, phenology and cambium activity in tropical dry forest trees. - IAWA J. 20: 239-247.

Carlquist, S. (1988): Comparative wood anatomy. - Springer Verlag, Berlin, Heidelberg, New York, $436 \mathrm{pp}$.

Cheadle, V. I., Gifford E. M. and Esau, K. (1953): A staining combination for phloem and contiguous tissues. - Stain Technol. 28: 49-53.

Dave, Y. S. and Rao, K. S. (1982a): Cambial activity in Mangifera indica L. - Acta Bot. Acad. Sci. Hung. 28: 73-79.

Dave, Y.S. and Rao, K. S. (1982b): Seasonal activity of vascular cambium in Gmelina arborea Roxb. - IAWA Bull., n. s. 3: 59-65.

Fahn, A. (1982): Plant anatomy. 3rd ed. - Pergamon Press, Oxford.

Fahn, A. and Sarnet, C. (1963): Xylem structure and annual rhythm of development in trees and shrubs of the desert. IV Shrubs. - Bull. Res. Counc. Israel 11D: 198-201.

Fahn, A., Waisel, Y. and Benjamini, L. (1968): Cambial activity in Acacia raddiana Savi. Ann. Bot. 32: 677-686.

Iqbal, M. and Ghouse, A. K. M. (1985): Impact of climatic variations on structure and activity of vascular cambium in Prosopis spicigera. - Flora 177: 147-156.

Kramer, P. J. and Kozlowski, T. T. (1979): Physiology of woody plants. - Acad. Press, New York.

Liphschitz, N. and Lev-Yadun, S. (1986): Cambial activity of evergreen and seasonal dimorphic around the Mediterranean. - IAWA Bull., n. s. 7: 145-153.

Little, C. H. A. (1975): Inhibition of cambial activity in Abies balsamea by internal water stress. Role of abscicic acid. - Can. J. Bot. 53: 3041-3050.

Paliwal, S. P. and Paliwal, G. S. (1990): Influence of climatic variations on the seasonal behaviour of vascular cambium in some Himalayan trees. III Rhododendron arboreum Smith. - Phytomorphol. 40: 257-271.

Rajput, K. S. (1997): Seasonal cambial activity and wood development in some timber trees growing in three different forest regions of Gujarat State. - Ph. D. Thesis, M. S., University of Baroda, Vadoara, India.

Rajput, K. S. and Rao, K. S. (1996): Structure of storied cambium in some tropical trees. - J. Indian Bot. Soc. 75: 103-304.

Rajput, K. S. and Rao, K. S. (1998): Occurrence of intercellular spaces in cambial rays. - Israel J. Plt. Sci. 46: 299-302.

Rajput, K. S. and Rao, K. S. (2000): Cambial activity and development of wood in Acacia nilotica (L.) Del. growing in different forests of Gujarat State. - Flora 195: 165-171.

Rao, K. S. and Dave, Y.S. (1984): Seasonal variations in the vascular cambium of Holoptelea integrifolia (Ulmaceae). - Beitr. Biol. Pflanzen. 59: 321-331.

Rao, K. S. and Rajput K. S. (1999): Seasonal behaviour of vascular cambium in teak (Tectona grandis L. f.) growing in moist deciduous and dry deciduous forests of Gujarat State. IAWA J. 20: 85-93.

Rao, K. S., Rajput, K. S. and Srinivas, T. (1996): Comparative structure of vascular cambium and its derivatives in some species of Sterculia. - IAWA J. 17: 311-318.

Waisel, Y. and Fahn, A. (1965): Effect of environment on wood formation and cambial activity in Robinia pseudoacacia. - New Phytol. 64: 436-442. 